\title{
Scorpion neurotoxin AalT-expressing Beauveria bassiana enhances the virulence against Aedes albopictus mosquitoes
}

\author{
Sheng-Qun Deng, Qun-Di Cai, Ming-Zhi Deng, Qiang Huang and Hong-Juan Peng*
}

\begin{abstract}
To improve the insecticidal efficacy of this entomopathogen Beauveria bassiana, the fungus was genetically modified to express an insect-specific scorpion neurotoxin AalT. The virulence of the recombinant B. bassiana strain (Bb-AalT) against Aedes albopictus adults (which occurs via penetration through the cuticle during spore germination or by conidia ingestion), and the larvae (by conidia ingestion) was measured with bioassays. The median lethal concentration $\left(L C_{50}\right)$ of $B b$-AalT against A. albopictus larvae was 313.3-fold lower on day 4 and 11.3-fold lower on day 10 than that of the wild type (WT). Through conidia feeding or body contact, Bb-AalT killed $50 \%$ of adult female mosquitoes at 3.9- or 1.9-fold reduced concentrations on day 4 and at 2.1- or 2.4-fold reduced concentrations on day 10. Compared with the results for the WT, the median lethal time $\left(\mathrm{LT}_{50}\right)$ of $B b$-AalT was reduced by $28.6 \%$ at $1 \times 10^{7} \mathrm{conidia} \mathrm{ml}^{-1}$ and

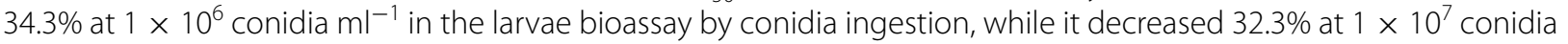

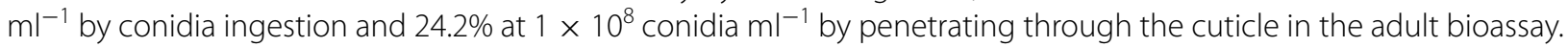
All the differences were significant. Our findings indicated that Bb-AalT had higher virulence and faster action than the WT in killing the larval and adult mosquitoes, and therefore, it is valuable for development as a commercial mosquito pesticide.
\end{abstract}

Keywords: Beauveria bassiana, Aedes albopictus, Scorpion neurotoxin, Virulence

\section{Introduction}

Mosquito-borne diseases create a significant burden every year. For example, malaria caused 438,000 deaths in 2015, and the dengue incidence has risen 30 -fold in the past 30 years around the world (WHO 2016). The Asian tiger mosquito Aedes albopictus transmits many viral infections, including the yellow fever, dengue and Chikungunya (Hochedez et al. 2006), as well as several filarial nematodes such as Dirofilaria immitis (Cancrini et al. 2003). Aedes albopictus is capable of hosting the Zika virus and is considered a potential vector for Zika transmission among humans (Paupy et al. 2009; Wong et al. 2013). Because more than half of the world's population

*Correspondence: floriapeng@hotmail.com; hongjuan@smu.edu.cn Department of Pathogen Biology, Guangdong Provincial Key Laboratory of Tropical Disease Research, and Key Laboratory of Prevention and Control for Emerging Infectious Diseases of Guangdong Higher Institutes, School of Public Health, Southern Medical University, Guangzhou 510515, Guangdong Province, China lives in areas where this mosquito species is present, sustained mosquito control efforts are important to prevent outbreaks from these diseases (Kamareddine et al. 2013).

Chemical insecticides have been used intensively as the primary strategy for controlling mosquito populations. However, this strong dependence on insecticides for mosquito control around the world and the use of these chemicals in agriculture have led to environmental pollution and toxic hazards to humans and other non-target organisms (Al-Sarar 2010). The physiological resistance of important mosquito vectors has been widely reported in recent years (Agra-Neto et al. 2014; Bilal et al. 2012; Labbe et al. 2007; Lima et al. 2011; Stenhouse et al. 2013; Zou et al. 2006).

Entomopathogenic fungi, such as Beauveria bassiana and Metarhizium anisopliae, have tremendous potential for use as pest biological control agents, particularly as alternatives to chemical pesticides (Lacey et al. 2001; Lomer et al. 2001). B. bassiana is an environmentally 
friendly fungus (Roberts and St Leger 2004; Thomas and Read 2007; Wang et al. 2004), and it is widely distributed and has a broad host range towards diverse insect species in nature (Reynolds and Samuels 1996). Many $B$. bassiana strains have been selected for vector and crop pest control, including house and fruit flies (Dimbi et al. 2003; Lecuona et al. 2005), mosquitoes (Bukhari et al. 2011; Clark et al. 1968; Garcia-Munguia et al. 2011), ticks (Kirkland et al. 2004), locusts, grasshoppers, and termites (Kassa et al. 2004; Mburu et al. 2009). However, the slow killing speed associated with these mycoinsecticides is a major deterrent to their commercial use and large-scale application, and thus they are unable to compete with faster-acting and cheaper chemical insecticides (Amsellem et al. 2002; St Leger et al. 1996).

AaIT is a single-chain neurotoxic polypeptide that is derived from the venom of the buthid scorpion Androctonus australis, and its strict selective toxicity for insects has long been documented (Dee et al. 1990; Zlotkin et al. 2000). It has been reported that the integration of AaIT into M. anisopliae for specific expression in the insect hemolymph after cuticle penetration resulted in 22-, 9-, and 16-fold increases in fungal toxicity to the tobacco hornworm Manduca sexta, the yellow fever mosquito Aedes aegypti, and the coffee berry borer Hypothenemus hampei, respectively (Pava-Ripoll et al. 2008; Wang and St Leger 2007). Similarly, B. bassiana expressing AaIT presented a 15 -fold increase in insecticidal activity against Masson's pine caterpillar Dendrolimus punctatus, and its median lethal times $\left(\mathrm{LT}_{50}\right)$ against the larvae of D. punctatus and Galleria mellonella were reduced by 24.4 and $40 \%$, respectively (Lu et al. 2008). In this study, we successfully improved the pathogenicity of $B$. bassiana against $A$. albopictus by engineering it to express the scorpion neurotoxin AaIT. The virulence of the recombinant fungi against adult A. albopictus (through cuticle penetration or conidia ingestion) and larvae (through conidia ingestion) was significantly improved.

\section{Materials and methods Mosquitoes}

The Foshan (Guangdong, China) strain of A. albopictus originated in Foshan, Guangdong Province, PRC, and it was established in our laboratory in 1981. All mosquitoes, including larval and adult mosquitoes, were maintained in humidified incubators at $25 \pm 1{ }^{\circ} \mathrm{C}$ on a 12 -h light: dark photocycle.

\section{Microbial strains and media}

The B. bassiana GIM3.428 strain (wild type, WT) was purchased from Guangdong Microbiology Culture Center and maintained on Czapek's agar (CDA) (w/v:
$3.0 \%$ sucrose, $0.3 \% \mathrm{NaNO}_{3}, 0.1 \% \mathrm{~K}_{2} \mathrm{HPO}_{4}, 0.05 \% \mathrm{KCl}$, $0.05 \% \mathrm{MgSO}_{4} \cdot 7 \mathrm{H}_{2} \mathrm{O}, 0.001 \% \mathrm{FeSO}_{4}$ and $2 \%$ agar) at $4{ }^{\circ} \mathrm{C}$ for preservation and at $25{ }^{\circ} \mathrm{C}$ for colony growth. The WT B. bassiana that was used as the parental strain in this study was sequentially cultured in Sabouraud dextrose broth (SDB) (w/v: $4 \%$ glucose, $1 \%$ peptone and $1 \%$ yeast extract) and glucose-mineral (GM) medium (w/v: $4 \%$ glucose, $0.4 \% \mathrm{NH}_{4} \mathrm{NO}_{3}, 0.3 \% \mathrm{KH}_{2} \mathrm{PO}_{4}$ and $0.3 \%$ $\mathrm{MgSO}_{4}$ ) for blastospore production. Escherichia coli Trans-T1 cells (Tansgen, Beijing, CHA), which are used for DNA manipulation, were cultured in Luria-Bertani medium containing $100 \mu \mathrm{g} / \mathrm{ml}$ ampicillin or $50 \mu \mathrm{g} / \mathrm{ml}$ kanamycin.

\section{Gene synthesis and vector construction}

The coding sequence of AaIT was synthesized by using B. bassiana-preferred codons and the Mcl1 signal peptide sequence (SP) was incorporated at the $5^{\prime}$ end of it for secretion expression (Genebank accession number: KY914486, Additional file 1: Figure S1a) (Wang and St Leger 2007). The synthesized gene was bracketed with EcoRI and XhoI sites and cloned into pBARGPE1, forming the plasmid pBARGPE1-AaIT (Additional file 1: Figure S1b). This plasmid retains a strong gpdA promoter to drive the insert's gene expression and Bar resistance coding sequence to express the selectable marker that would provide resistance to phosphinothricin (PPT). The recombinant plasmid pBARGPE1-AaIT was transformed into E. coli Trans-T1 for propagation, followed by isolation with Plasmid Mini Kit I (Omega, Norcross, GA). After it was linearized with ScaI (Thermo Fisher Scientific, Waltham, MA), the plasmid was purified using a Cycle-Pure Kit (Omega, Norcross, GA) and dissolved in $\mathrm{dd}-\mathrm{H}_{2} \mathrm{O}$ at a concentration of $100 \mathrm{ng} / \mu \mathrm{l}$ for blastospore electro-transformation.

\section{Blastospore preparation}

Beauveria bassiana conidia formation was triggered by culturing the fungi in SDB with $120 \mathrm{rpm}$ shaking at $25{ }^{\circ} \mathrm{C}$ for $48 \mathrm{~h}$, and then $5 \mathrm{ml}$ of this fungal culture was transferred to $50 \mathrm{ml}$ of GM medium for $12 \mathrm{~h}$ with shaking under the same conditions. The resulting cultures were filtered through layers of sterile cotton to get rid of the hyphae, and the blastospores were harvested by a $10 \mathrm{~min}$ centrifugation cycle at $5000 \times g$ and $4{ }^{\circ} \mathrm{C}$, followed by two washes with $\mathrm{dd}-\mathrm{H}_{2} \mathrm{O}$. The harvested blastospores were suspended with $0.5 \mathrm{ml}$ of $1 \mathrm{M}$ sorbitol and counted with a hemocytometer. Each suspension was mixed with an appropriate amount of $80 \%$ sterile glycerol to dilute the blastospore concentration to $1 \times 10^{8} / \mathrm{ml}$, and the samples were ultimately stored at $-80{ }^{\circ} \mathrm{C}$ for sequential use in electro-transformation. 


\section{Electroporation}

The stored blastospores were precipitated after centrifugation at $5000 \times g$ and $4{ }^{\circ} \mathrm{C}$ for $5 \mathrm{~min}$, and they were suspended in the mixture containing $10 \mu \mathrm{l}$ of linearized pBARGPE1-AaIT and $90 \mu \mathrm{l}$ of ice-cold $1 \mathrm{M}$ sorbitol. The suspension was then transferred into a $0.2 \mathrm{~mm}$ prechilled cuvette and pulsed using an electroporator (Bio-Rad, CA, USA) at a field strength of $2 \mathrm{kV} \mathrm{cm}^{-1}$ for $5 \mathrm{~ms}$ (milliseconds). The pulsed suspension was transferred into a new Eppendorf tube. The residue in the cuvette was washed twice with $150 \mu \mathrm{l}$ of $1 \mathrm{M}$ ice-cold sorbitol and $300 \mu \mathrm{l}$ of washing solution, and the washing solution was also added to the Eppendorf tube. The final suspension was incubated for $2 \mathrm{~h}$ at $25^{\circ} \mathrm{C}$ and then $150 \mu \mathrm{l}$ aliquots were smeared on CDA plates containing $150 \mu \mathrm{g} / \mathrm{ml}$ PPT.

\section{Isolation of recombinants}

Each transformation product was grown on CDA plates containing $150 \mu \mathrm{g} / \mathrm{ml} \mathrm{PPT}$ at $25{ }^{\circ} \mathrm{C}$. The putative recombinants were picked out and subcultured for three generations on CDA with $150 \mu \mathrm{g} / \mathrm{ml}$ PPT. The genomic DNA of every generation was extracted from the 4-day-old colonies according to a documented method (Raeder and Rroda 1985) and used as PCR templates to detect the AaIT gene presence in the recombinants with SP-AaIT-F and SP-AaIT-R primers (5'-CCCAAGCTTATGCGTGAACTTTCTTCGGT- ${ }^{\prime}$ and $5^{\prime}$-CCCTCGAGTTAGTTGATGATGGTGGTAT- $3^{\prime}$, respectively). To verify the mitotic stability of their PPT resistance, the recombinants were subcultured for three generations on CDA without PPT at $25^{\circ} \mathrm{C}$, and finally, they were subcultured on CDA with $400 \mu \mathrm{g} / \mathrm{ml}$ PPT at $25^{\circ} \mathrm{C}$. Genomic DNAs were extracted from the 4-day-old colonies from the last subculture and then analyzed by PCR. A stable recombinant strain named $B b$-AaIT was selected for the subsequent experiments.

\section{Identification of AalT expression in Bb-AalT}

The WT and $B b$-AaIT strains were grown in CDA for 4 days. Dead female adult mosquitoes that were infected by ingesting WT or $B b$-AaIT conidia were maintained at $25{ }^{\circ} \mathrm{C}$ at saturated humidity for 4 days. To verify the transcription of AaIT gene in Bb-AaIT, the total RNAs were extracted from the CDA culture supernatant or infected mosquitoes using an RNeasy mini plant kit (Qiagen, Duesseldorf, GER), and they were subjected to reverse transcription with random primers and then PCR with the primers RT-AaIT-F and RT-AaIT-R (5'-CTTTCTTCGGTTCTCGCCCT- ${ }^{\prime}$ and 5'-CCTTAT CGGCGTAGTGGACC- $3^{\prime}$, respectively).

A polyclonal antibody against AaIT that was expressed by $E$. coli BL21 (DE3) was derived from rabbits and used to detect the expression of AaIT in the Bb-AaIT or WT grown in CDA or in the infected mosquitoes by western blotting. To verify the translation of AaIT gene in $B b$-AaIT, the fungi that were precipitated from the CDA culture supernatant and the infected mosquitoes were ground under liquid nitrogen in mortars for $5 \mathrm{~min}$. Then, $1 \mathrm{ml}$ of cell lysis solution (Beyotime, Shanghai, CHA) was added to the mortars, and the samples were further ground on ice for another $5 \mathrm{~min}$. The ground-up mix was transferred to an Eppendorf tube, and after centrifugation at 12,000 rpm for $5 \mathrm{~min}$, the pellets were reconstituted in sterile $\mathrm{ddH}_{2} \mathrm{O}$. The concentrations of the total protein extracts were measured by Nanodrop (Thermo Fisher Scientific, Waltham, MA). Fifty microgram of total protein extracts were loaded for SDS-PAGE, and then western blotting was performed.

\section{Bioassays}

The conidia of the Bb-AaIT and WT strains were harvested from the CDA plates with sterile cotton swabs, resuspended in $\mathrm{ddH}_{2} \mathrm{O}$, and counted with a hemocytometer. Three bioassays were conducted to compare the virulence of the $B b$-AaIT and WT strains to the second-instar larvae of Aedes albopictus infection through conidia ingestion (assay 1), 3-day-old (3 days after emergence) female adult mosquitoes infection through conidia ingestion (assay 2) or through cuticle contact (assay 3). In assay 1 , conidia suspensions of $1 \times 10^{5}$ conidia $/ \mathrm{ml}$ (low), $1 \times 10^{6}$ conidia/ml (middle) and $1 \times 10^{7}$ conidia/ $\mathrm{ml}$ (high) of $B b$-AaIT and WT were added to the cups containing $20 \mathrm{~s}$-instar A. albopictus larvae in $30 \mathrm{ml}$ of double distilled water, respectively. Each treatment was performed in three replicates, and the mortality levels of the larvae were recorded every $24 \mathrm{~h}$ for 10 days. In assays 2 and 3, the 3-day-old adult female mosquitoes were anesthetized with a multiunit $\mathrm{CO}_{2}$ anesthetizing system (Vessey et al. 2008). In assay 2, 30 anesthetized female mosquitoes in each group were transferred to the plastic container immediately and fed with $10 \%$ glucose containing $B b$-AaIT and WT conidia. The conidia had different concentrations of $1 \times 10^{6}$ conidia/ml (low), $1 \times 10^{7}$ conidia/ml (medium) and $1 \times 10^{8}$ conidia/ml (high), respectively, and the control group was fed pure $10 \%$ glucose. The tests were conducted in the laboratory at $25^{\circ} \mathrm{C}$. In assay 3, 30 anesthetized female mosquitoes in each group were placed on the $50 \mathrm{~cm}^{2}$ filter paper that had absorbed $3 \mathrm{ml}$ of conidial suspension at $1 \times 10^{5}$ conidia/ $\mathrm{ml}$ (low), $1 \times 10^{6}$ conidia/ml (middle) and $1 \times 10^{7}$ conidia/ml (high) or $0.02 \%$ Tween 80 (control) for $10 \mathrm{~s}$. The mosquitoes were transferred separately to different plastic containers. The contaminated mosquitoes or control mosquitoes were maintained on a $10 \%$ glucose diet in plastic containers at $25{ }^{\circ} \mathrm{C}$. Each treatment was performed in three replicates and the mortality levels of the 
adult female mosquitoes were recorded every $12 \mathrm{~h}$ during assays 2 and 3 .

A Kaplan-Meier survival analysis and a log-rank test were used to compare the differences between these two strains at three concentrations and to compare the difference between these two strains at each given concentration. A time-concentration-mortality (TCM) model analysis (Feng et al. 1998; Nowierski et al. 1996) was used to calculate the median lethal concentration $\left(\mathrm{LC}_{50}\right)$ and the median lethal time $\left(\mathrm{LT}_{50}\right)$ in the treated mosquitoes. All the tests were conducted with IBM SPSS (ver. 20.0) and DPS software (ver. 7.05) (Tang and Feng 2007).

\section{Results}

\section{Detection of AalT gene presence and the mitotic stability} of the $B b$-AalT strain

Transformation of the competent blastopores of WT with linearized plasmid pBARGPE1-AaIT produced one transgenic colony on the CDA plate containing $150 \mu \mathrm{g} /$ $\mathrm{ml}$ PPT. The tansformant was able to grow on CDA plate containing $150 \mu \mathrm{g} / \mathrm{ml} \mathrm{PPT}$ for three generations. After three rounds of subculturing on PPT-free CDA plates, the tansformant be capable of growing on the CDA plate containing $400 \mu \mathrm{g} / \mathrm{ml}$ PPT. The genomic DNA of the colonies grown on the plate during each generation were extracted and used as PCR templates to detect the presence of the AaIT gene in Bb-AaIT. The expected PCR fragments from all the $B b$-AaIT samples appeared on the agarose gel, but not the WT (Additional file 1: Figure S2), which confirmed the consistent heredity of the AaIT gene in the $B b$-AaIT genome.

\section{Detection of AalT expression in the Bb-AalT strain}

The WT and $B b$-AaIT strains were grown in CDA for 4 days at $25{ }^{\circ} \mathrm{C}$ and precipitated with centrifugation, and they were kept for analysis. The fungal outgrowths were those of a typical B. bassiana, and they appeared on the dead female mosquitoes that were infected through conidial ingestion after being maintained at $25{ }^{\circ} \mathrm{C}$ at saturated humidity for 4 days (Fig. 1c). The total RNAs and proteins of the WT and $B b$-AaIT from the culture supernatant or infected mosquitoes were extracted and analyzed by RT-PCR (Fig. 1a) or western blotting (Fig. 1b). This result indicated that the recombinant strain expressed the AaIT toxin consistently, but not the WT strain.

\section{Bioassay results for the Bb-AalT and WT against larval or adult mosquitoes}

Bioassays for the pathogenicity of the $B b$-AaIT and WT against the 2-instar larvae and the female adults of Aedes albopictus mosquitoes (through cuticle penetration or conidia ingestion) were conducted at low, middle, and high conidial concentrations. Significant differences

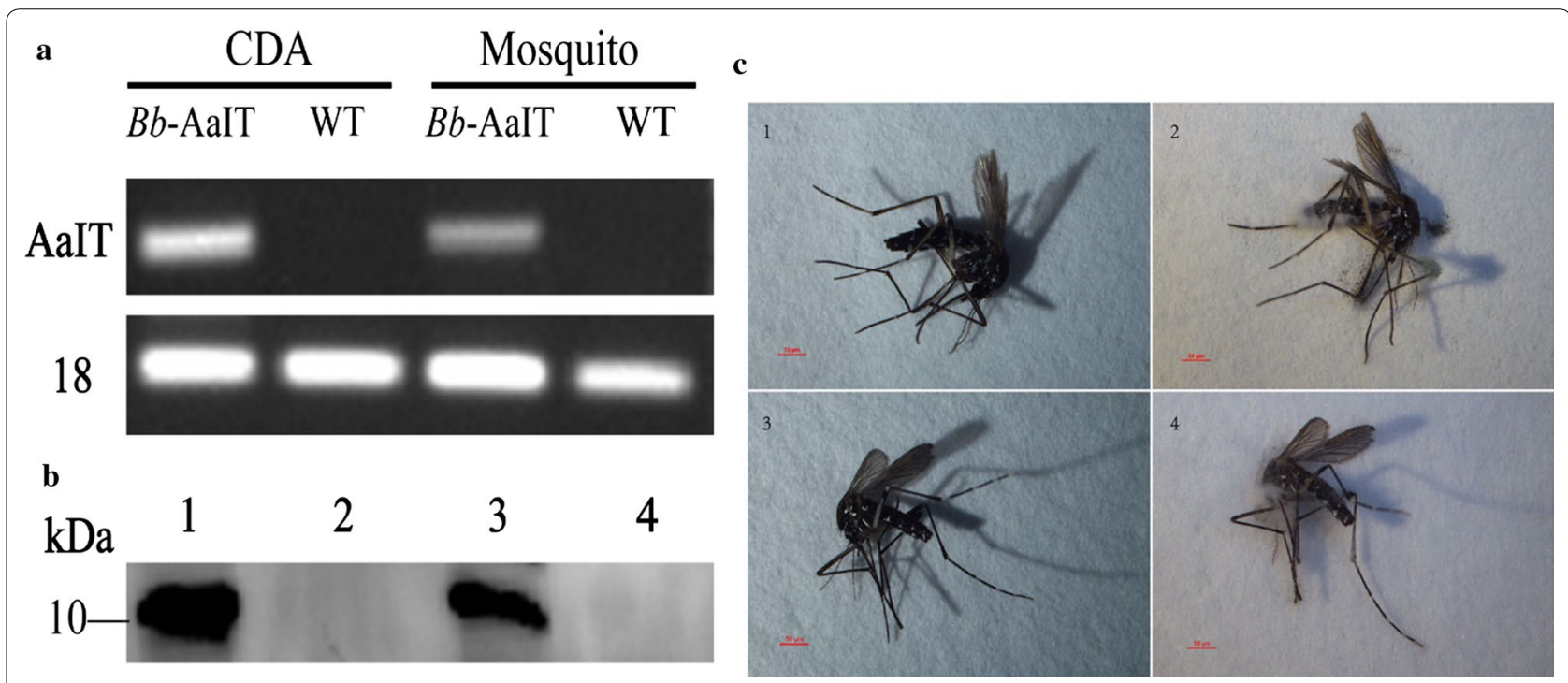

Fig. 1 Evidence for AalT expression in the Bb-AalT strain. a RT-PCR detection of AalT gene transcription in Bb-AalT collected from the infected dead mosquitoes and the CDA with positive results, and in the WT control with negative results. The $18 \mathrm{~S}$ rRNA was detected for the loading control. $\mathbf{b}$ Western blot detection of AalT expression in Bb-AalT and the WT with a polyclonal antibody against AalT from different samples. Lane 1, culture supernatant from Bb-AalT grown in CDA for 4 days with a positive result; Lane 2, culture supernatant from WT grown in CDA for 4 days with a negative result; and Lane 3, the dead female mosquitoes infected by $B b$-AalT and incubated at $25^{\circ} \mathrm{C}$ for another 4 days. Lane 4 , the dead female mosquitoes infected by the WT and incubated at $25^{\circ} \mathrm{C}$ for another 4 days. c The dead female mosquitoes were infected by Bb-AalT or WT through conidial ingestion. Fungal outgrowths were not observed in the uncultured dead mosquitoes ( 1 and 3), and typical fungal outgrowths were observed on the dead mosquitoes that were infected by Bb-AalT (2) and the WT (4) after 4 days of incubation at $25^{\circ} \mathrm{C}$ and saturated humidity. Bars, $50 \mu \mathrm{m}$ 
were found among the different $B b$-AaIT or WT treatment concentrations (Table 1). The mortalities generally increased with the increased conidial concentration and the post-treatment time for both $B b$-AaIT and WT (Fig. 2).

Table 1 Results of the log-rank test for the different concentrations of Bb-AaIT or the WT against Aedes albopictus (larval or female adult mosquitoes) in assays 1-3

\begin{tabular}{lllll}
\hline Assays & Fungal strains & $\mathbf{X}^{\mathbf{2}}$ & Df & $\boldsymbol{P}$ \\
\hline Assay 1 & Bb-AalT & 10.155 & 2 & 0.006 \\
& WT & 8.402 & 2 & 0.015 \\
Assay 2 & Bb-AalT & 50.706 & 2 & $<0.001$ \\
& WT & 39.299 & 2 & $<0.001$ \\
Assay 3 & Bb-AalT & 30.904 & 2 & $<0.001$ \\
& WT & 18.077 & 2 & $<0.001$ \\
\hline
\end{tabular}

$P<0.05$ means that the difference is significant
In assay 1 , significant differences were found between the mortalities of $B b$-AaIT and the WT-treated larvae at each given concentration (Table 1). That is, the larvae that were treated with $B b$-AaIT tended to die faster than those treated with the WT (Fig. 2a), and the difference was significant (Table 2). In assays 2 and 3, $B b$ AaIT-treated mosquitoes tended to die faster than those treated with the WT at the high concentration and the difference was significant; however, no significant difference was found between the Bb-AaIT and WT-treated adult mosquitoes at the low and middle concentrations (Fig. 2b, c; Table 2).

The median lethal concentrations were calculated by using the TCM model (Feng et al. 1998; Qin et al. 2010). No significant heterogeneity was detected for each of the fitted TCM relationships $(P>0.05$ in Hosmer-Lemeshow tests for the goodness of fit). As a result of the modeling analyses, the $\mathrm{LC}_{50} \mathrm{~s}$ of $\mathrm{Bb}$-AaIT and the WT against the larvae were estimated to be $3.04 \times 10^{7}$
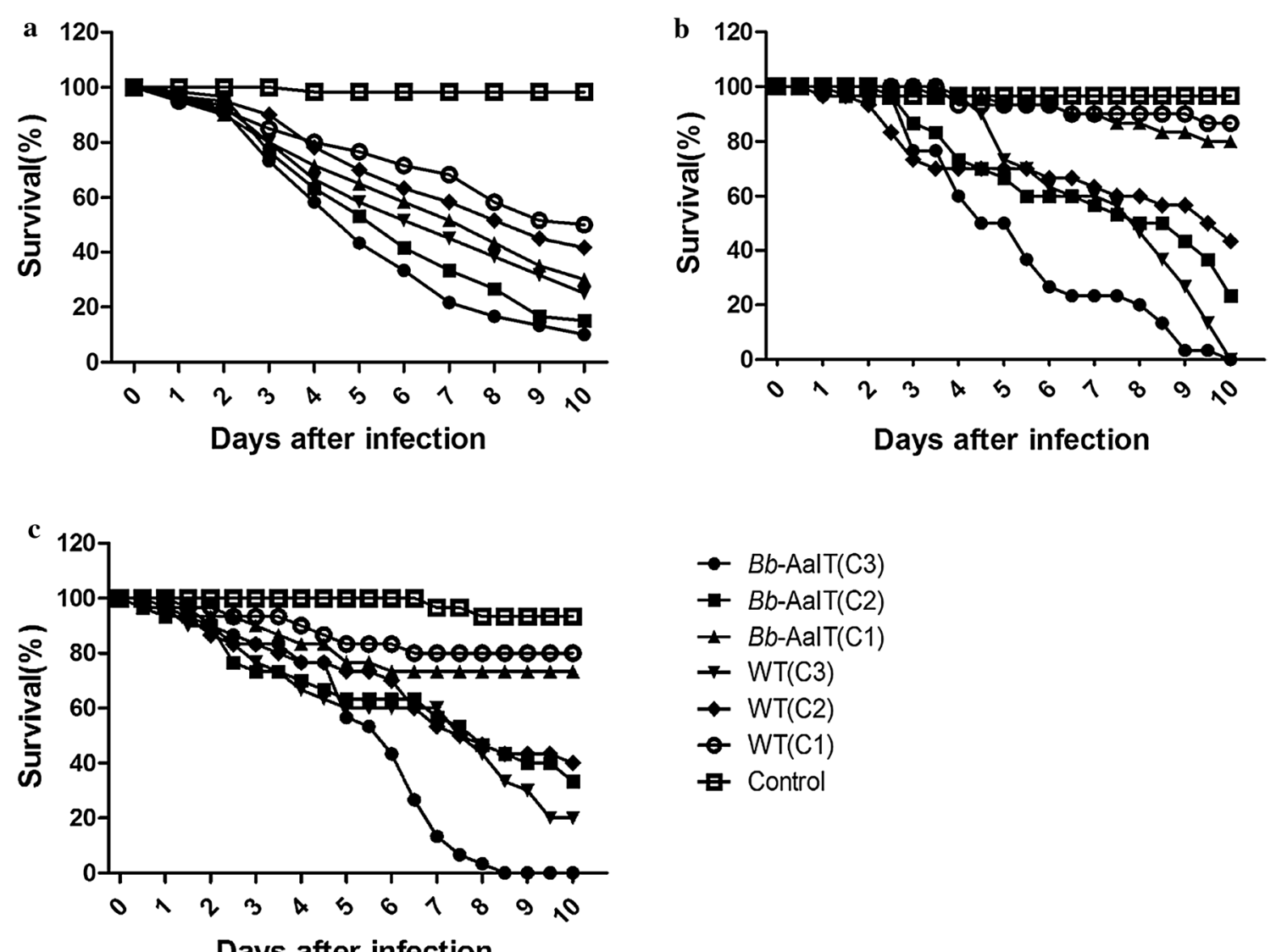

\section{Days after infection}

Fig. 2 Survival curves of larval and adult mosquitoes for different Bb-AalT and WT treatments. a The survival curve of Aedes albopictus larvae when treated with (C1) $1 \times 10^{5}$, (C2) $1 \times 10^{6}$ and (C3) $1 \times 10^{7}$ conidia $\mathrm{ml}^{-1}$ suspensions of Bb-AalT and the WT. b The survival curve of Aedes albopictus female adults that were infected by conidia ingestion with (C1) $1 \times 10^{5}$, (C2) $1 \times 10^{6}$ and (C3) $1 \times 10^{7}$ conidia ml $^{-1}$ suspensions of Bb-AalT and WT. c The survival curve of Aedes albopictus female adults that were infected through cuticle contact with $3 \mathrm{ml}$ of (C1) $1 \times 10^{6}$, (C2) $1 \times 10^{7}$ and (C3) $1 \times 10^{8}$ conidia $\mathrm{ml}^{-1}$ suspensions containing Bb-AalT and WT that were sprayed on $50 \mathrm{~cm}^{2}$ filter paper 
Table 2 Results of the log-rank test on the different fungal strains Bb-AalT and WT against Aedes albopictus (larval or female adult mosquitoes) at each given concentration in assays 1-3

\begin{tabular}{llrll}
\hline Assays & Concentrations $\left(\right.$ conidial $\mathbf{~ m}^{-\mathbf{1}}$ ) & $\mathbf{X}^{\mathbf{2}}$ & $\mathbf{d f}$ & $\boldsymbol{P}$ \\
\hline Assay 1 & $1 \times 10^{7}$ & 5.999 & 1 & 0.014 \\
& $1 \times 10^{6}$ & 10.898 & 1 & 0.001 \\
& $1 \times 10^{5}$ & 4.677 & 1 & 0.031 \\
Assay 2 & $1 \times 10^{7}$ & 9.574 & 1 & 0.002 \\
& $1 \times 10^{6}$ & 1.365 & 1 & 0.243 \\
& $1 \times 10^{5}$ & 0.451 & 1 & 0.502 \\
Assay 3 & $1 \times 10^{8}$ & 10.612 & 1 & 0.001 \\
& $1 \times 10^{7}$ & 0.160 & 1 & 0.689 \\
& $1 \times 10^{6}$ & 0.399 & 1 & 0.528 \\
\hline
\end{tabular}

$P<0.05$ means that the difference is significant and $9.52 \times 10^{9}$ conidia $\mathrm{ml}^{-1}$ on day 4 and then they decreased to $1.47 \times 10^{3}$ and $1.65 \times 10^{4}$ conidia $\mathrm{ml}^{-1}$ on day 10 (Fig. 3a). For assay 2, the $\mathrm{LC}_{50}$ estimated for $\mathrm{Bb}$ $\mathrm{AaIT}$ and the WT against female mosquitoes that were infected through the cuticle dropped from $1.13 \times 10^{7}$ and $4.39 \times 10^{7}$ conidia $\mathrm{ml}^{-1}$ on day 4 to $3.91 \times 10^{5}$ and $8.38 \times 10^{5}$ conidia $\mathrm{ml}^{-1}$ on day 10 (Fig. $3 \mathrm{~b}$ ), respectively. For assay 3 , the $\mathrm{LC}_{50}$ estimated for $\mathrm{Bb}$-AaIT and the WT against female mosquitoes infected through conidial ingestion were $1.71 \times 10^{8}$ and $3.26 \times 10^{8}$ conidia $\mathrm{ml}^{-1}$ on day 4 , and then decreased to $3.96 \times 10^{6}$ and $9.56 \times 10^{6}$ conidia ml ${ }^{-1}$ on day 10 (Fig. 3c), respectively. The $\mathrm{LC}_{50} \mathrm{~s}$ of the $B b$-AaIT conidia decreased with the treatment time in assays 1, 2 and 3 from 313.3-, 3.9- and 1.9-fold on day 4 to $11.3-, 2.1$ - and 2.4-fold on day 10, respectively, when compared with those of the WT conidia.
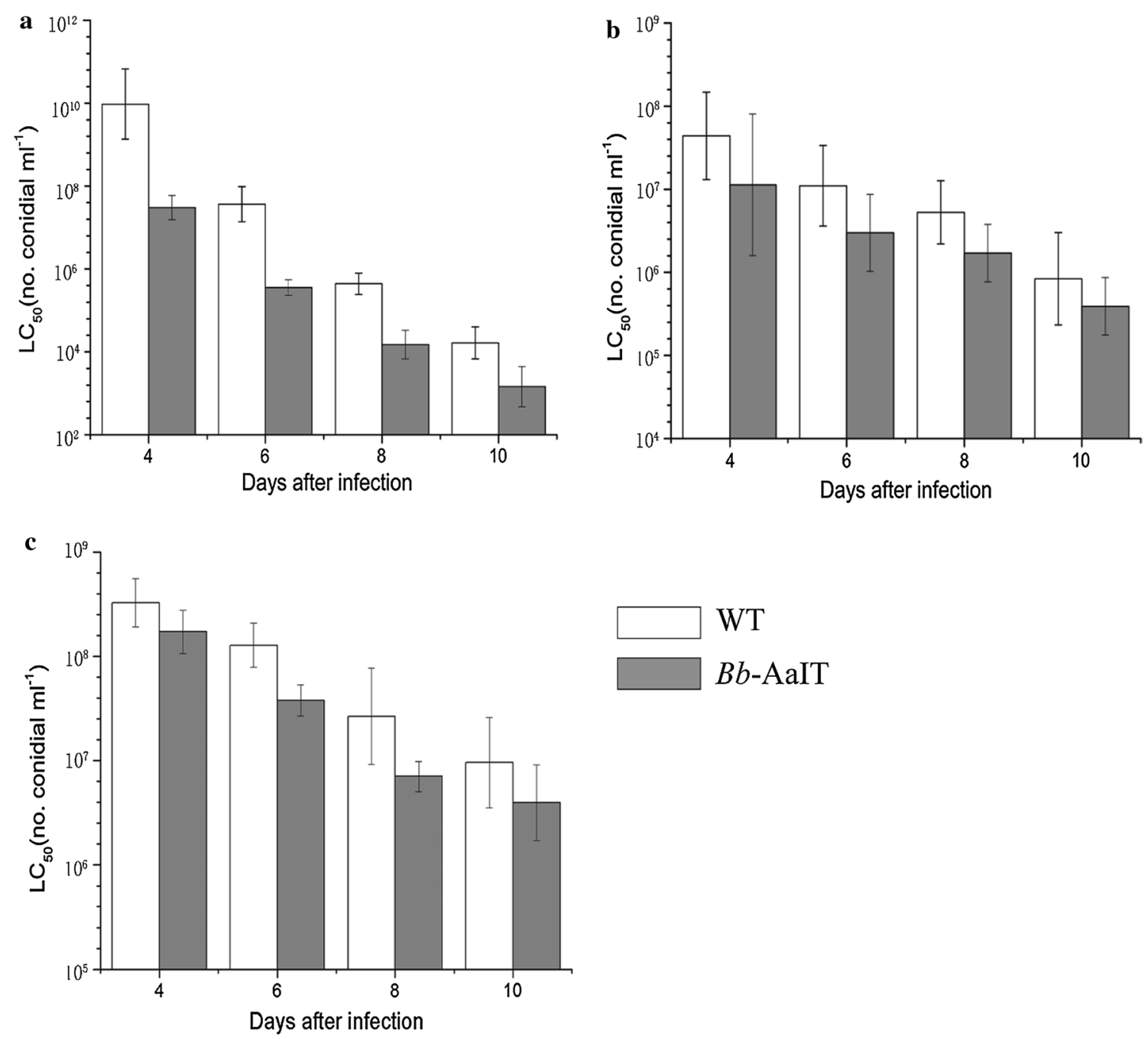

Fig. $3 L C_{50}$ of WT and Bb-AalT strains against larval or adult mosquitoes. Error bars: \pm SE. Three bioassays were conducted to compare the virulence of the Bb-AalT and WT strains as follows: a assay 1, the second-instar larvae of Aedes albopictus infection through conidia ingestion. (b, c) 3-day-old (3 days after emergence) female adult mosquito infection through cuticle contact (b, assay 2) or through conidia ingestion (c, assay 3) 
The median lethal times were estimated by using the TCM model. The $\mathrm{LT}_{50} \mathrm{~S}$ of $\mathrm{Bb}$-AaIT and WT could not be calculated at the low concentration because no more than half the quantity of lethal larvae or adult mosquitoes could be observed at the final time. The $\mathrm{LT}_{50}$ trends for $B b$-AaIT were lower than those of the WT at the middle and high concentrations in the three assays. For instance, the $\mathrm{LT}_{50} \mathrm{~S}$ of the treated larvae were 7.7 and 6.7 days for the WT and 5.5 and 4.4 days for Bb-AaIT at the middle and high concentrations, respectively (Table 3 ). $\mathrm{The}^{\mathrm{LT}} \mathrm{T}_{\mathrm{S}} \mathrm{S}$ for $B b$-AaIT were reduced by 28.6 and $34.3 \%$ at these two concentrations in assay 1 when compared with that of WT. The $\mathrm{LT}_{50} \mathrm{~s}$ of the treated adult female mosquitoes at the middle and high concentrations were 9.9 and 6.2 days for the WT and 8.8 and 4.2 days for Bb-AaIT, respectively, in assay 2, 9.8 and 6.2 days for WT and 7.5 and 4.7 days for $B b$-AaIT, in assay 3 (Table 3 ). The $\mathrm{LT}_{50}$ differences between the two strains reached 11.1, and $32.3 \%$ in assay 2 and 23.5 and $24.2 \%$ in assay 3 at middle and high concentrations, respectively, but no significant difference was found for the middle concentration from both assays. This difference indicated the substantial impact of the expressed AaIT toxin on the survival of the tested larvae and adult mosquitoes.

\section{Discussion}

The insect-specific toxin AaIT is toxic to larval and adult mosquitoes (Dee et al. 1990; Higgs et al. 1995), and it specifically affects the voltage-gated sodium channels (VGSCs) in insects (Gurevitz et al. 2007). Although VGSCs in different taxa show high similarities, AaIT exhibits high specific sensitivity to insects and distinguishes between insects and mammals, which makes it particularly well-suited for the development of safe bioinsecticides (Zlotkin et al. 2000). AaIT induces the fast excitatory paralysis caused by a presynaptic effect, or the induction of a repetitive firing in the terminal branches of the insect's motor nerves, which results in the massive and uncoordinated stimulation of the respective skeletal muscles (Gurevitz et al. 2007; Zlotkin et al. 2000). The adult mosquitoes that were infected by $M$. anisopliae expressing AaIT demonstrated pre-lethal effects including spasmodic leg and wing movements several hours before death, and they invariably died with extended wings, which is indicative of the muscle contraction resulting from AaIT (Wang and St Leger 2007).

In this study, the amino acid sequence of the AaIT protein was obtained from the Swiss-Prot database. In the optimized sequence, we used the preferred codons of $B$. bassiana to encode all of the given amino acids, which would improve the gene expression level (Elena et al. 2014). The coding sequence of AaIT was synthesized and cloned into pBARGPE1 (Additional file 1: Figure $\mathrm{S} 1 \mathrm{~b})$. The strong gpdA promoter can drive the exogenous gene expression efficiently, which had been extensively and successfully applied for the transgenic gene expression in M. anisopliae and B. bassiana (Lu et al. 2008; St et al. 1996). Furthermore, the AaIT gene was genetically induced into the genome of the wild type $B$. bassiana to enhance its virulence to mosquitoes, and the mitotically stable transformant $B b$-AaIT could successfully express this exogenous toxin. The virulence of $B b$-AaIT and the wild type to larval (with infection through conidia ingestion) or adult mosquitoes (infection through cuticle or conidia ingestion) were compared at low, middle and high concentrations by survival analysis. For both $B b$ AaIT and the WT, the virulence was increased with the increase in the concentration, and the difference was significant. $B b$-AaIT-treated larvae tended to die faster than those treated with the WT at each given concentration; and $B b$-AaIT-treated adult mosquitoes only died faster than those treated with the WT at the high concentration. The difference was significant.

The TCM modeling can reflect the integrity and objectivity of the bioassay data, which accounts for the effects of the conidial concentration and post-treatment time as well as the interaction of both variables (Feng et al. 1998; Nowierski et al. 1996). The robust TCM modeling analysis clearly differentiated the $\mathrm{LC}_{50}$ and $\mathrm{LT}_{50}$ trends in $\mathrm{Bb}$ AaIT and the WT during the three bioassays on larvae and adult mosquitoes. In terms of the $\mathrm{LC}_{50}, \mathrm{Bb}$-AaIT was substantially improved in terms of virulence compared to the WT strain. With the same treatments, the $\mathrm{LT}_{50} \mathrm{~S}$ of the $B b$-AaIT strain at the middle and high conidial

Table 3 The median lethal times $\left(\mathrm{LT}_{50} \mathrm{~s}\right.$ ) of the fungal strains Bb-AalT and WT against Aedes albopictus (larval or female adult mosquitoes) at middle and high concentrations in assays 1-3

\begin{tabular}{|c|c|c|c|c|c|c|}
\hline \multirow[t]{2}{*}{ Concentrations (conidial ml $\mathrm{m}^{-1}$ ) } & \multicolumn{2}{|c|}{ Assay $1\left(\mathrm{LT}_{50}\right.$, days) } & \multicolumn{2}{|c|}{ Assay 2 (LT ${ }_{50}$, days) } & \multicolumn{2}{|c|}{ Assay 3 (LT $_{50}$, days) } \\
\hline & $1 \times 10^{7}$ (High) & $1 \times 10^{6}$ (Middle) & $1 \times 10^{7}$ (High) & $1 \times 10^{6}$ (Middle)* $^{*}$ & $1 \times 10^{8}$ (High) & $1 \times 10^{7}$ (Middle) ${ }^{*}$ \\
\hline Bb-AalT & 4.4 & 5.5 & 4.2 & 8.8 & 4.7 & 7.5 \\
\hline WT & 6.7 & 7.7 & 6.2 & 9.9 & 6.2 & 9.8 \\
\hline
\end{tabular}

*The difference of $\mathrm{LT}_{50}$ for two strains is not significant 
concentrations were shortened by $11.1-34.3 \%$, respectively, compared to the WT strain. Apparently, the higher level of virulence and the faster action of $B b$-AaIT were attributed to the insecticidal activity of the AaIT that was expressed in the ingested conidia. In other words, the $B b$ AaIT strain was capable of killing the larvae by ingesting the conidia in suspension and killing adult mosquitoes through both cuticle infection and conidia ingestion at a higher efficiency than the wild-type strain.

When fungal spores are applied to an aquatic habitat, which is typical for mosquito larvae, the nutrients in the water are usually sufficient for stimulating the germination of the spores following water intake (Bukhari et al. 2011; Hegedus and Khachatourians 1995). The scorpion toxin should be delivered into the insect circulatory system since it acts upon the injection of the scorpion venom into the prey or enemy (Matsumoto et al. 2014). For mosquito larvae, the primary path of infection was through the feeding, respiratory apparatus (Miranpuri and Khachatourians 1991) or cuticle. In this study, after the mosquito larvae were infected by $B b$-AaIT, the scorpion toxin AaIT was delivered into the hemolymph by spore germination, which sped up the death of the mosquito larvae. When adult mosquitoes were exposed to $B b$-AaIT by body contact, the fungal infection started from the adhesion of the conidia to the host cuticle, followed by germination and cuticle penetration into the hemocoel (Feng et al. 1994). Similarly, the expression of AaIT accelerated the death of adult mosquitoes. Moreover, when the adult mosquitoes were infected by feeding on $10 \%$ glucose solution containing $B b$-AaIT conidia, the AaIT was expressed and released into the midgut environment by the ingested conidia, which accelerated the death of the infected adult mosquitoes (Matsumoto et al. 2014).

The effective use of fungi as bio-insecticides is largely dependent on the persistent activity of fungal spray residues, which can be influenced by some factors including the formulation, substrate, fungal isolate, UV radiation and the prevailing abiotic conditions (Acharya et al. 2015; Blanford 2012; Darbro and Thomas 2009; Jackson et al. 2010; Jaronski 2010; Jenkins and Thomas 1996; Morleydavies et al. 1996). A recent study stated that the persistence of $B$. bassiana products was reduced in the field compared with that observed in the laboratory; conidia remained viable for up to 3 months under laboratory conditions, but for only 1-2 weeks in the field (Acharya et al. 2015). An appropriate formulation is needed to ensure the even distribution of conidia throughout the treated area and to improve the persistent activity of conidia that were exposed to various environmental conditions. In this study, the transgenic strain $(B b$-AaIT) was found to be significantly effective at controlling larval and adult mosquitoes. However, additional studies are required to find an appropriate formulation to exert the maximum potential entomopathogenic activity of $B b$-AaIT against mosquitoes.

In conclusion, our study demonstrated that the virulence of wild type $B$. bassiana can be improved significantly by introducing the insect-specific toxin gene AaIT into the genome to express the exogenous toxin in the fungus. This recombinant $B$. bassiana was valuable for mosquito control, and even for other pest control.

\section{Additional file}

Additional file 1: Figure S1. AalT Gene synthesis and plasmid construction. Figure S2. Identification of genetic stability of AalT gene in the different generations of recombinant Beauveria bassiana.

\section{Abbreviations}

$\mathrm{LC}_{50}$ : the median lethal concentration; WT: wild type strain; $\mathrm{LT}_{50}$ : the median lethal time; CDA: Czapek's agar; SDB: Sabouraud dextrose broth; GM: glucosemineral; PPT: phosphinothricin; TCM: time-concentration-mortality; UV: ultraviolet; VGSCs: the voltage-gated sodium channels.

\section{Authors' contributions}

SQD: Construction of plasmids, fugal culture, mosquito breeding, RT-PCR and western blotting detection of expression of proteins, bioassays, figures drafting, analysis and interpretation of the data, manuscript drafting and submission; QDC: Construction of plasmids, fugal culture, mosquito breeding; MZD: Fugal culture, mosquito breeding, bioassays; $\mathrm{QH}$ : analysis and interpretation of the data; HJP: study conception and design, supervision of the research group, funding support, and manuscript drafting. All authors read and approved the final manuscript.

\section{Competing interests}

The authors declare that they have no competing interests.

\section{Ethics approval and consent to participate}

Our only experimental animal is Aedes albopictus, which does not involve animal ethical issues.

\section{Funding}

This study was funded by the National Natural Science Foundation of China (No. 81271866, 81572012), the Guangdong Province Universities and Colleges Pearl River Scholar Funded Scheme (2014), the Guangdong Provincial Natural Science Foundation Key Project (2016A030311025), and the Guangzhou health and medical collaborative innovation major special project (201604020011) to HJP.

\section{Publisher's Note}

Springer Nature remains neutral with regard to jurisdictional claims in published maps and institutional affiliations.

Received: 26 May 2017 Accepted: 1 June 2017

Published online: 09 June 2017

\footnotetext{
References

Acharya N, Seliga RA, Rajotte EG, Jenkins NE, Thomas MB (2015) Persistence and efficacy of a biopesticide against the house fly, on typical structural substrates of poultry houses. Biocontrol Sci Tech 25:1-41

Agra-Neto AC, Napoleão TH, Pontual EV, Santos ND, Luz Lde A, de Oliveira CM, de Melo-Santos MA, Coelho LC, Navarro DM, Paiva PM (2014) Effect of Moringa oleifera lectins on survival and enzyme activities of Aedes aegypt
} 
larvae susceptible and resistant to organophosphate. Parasitol Res 113:175-184. doi:10.1007/s00436-013-3640-8

Al-Sarar AS (2010) Insecticide resistance of Culex pipiens (L.) populations (Diptera: (Culicidae) from Riyadh city, Saudi Arabia: status and overcome. Saudi J Biol Sci 17:95-100. doi:10.1016/j.sjbs.2010.02.001

Amsellem Z, Cohen BA, Gressel J (2002) Engineering hypervirulence in a mycoherbicidal fungus for efficient weed control. Nat Biotechnol 20:1035-1039. doi:10.1038/nbt743

Bilal H, Hassan SA, Khan IA (2012) Isolation and efficacy of entomopathogenic fungus (Metarhizium anisopliae) for the control of Aedes albopictus Skuse larvae: suspected dengue vector in Pakistan. Asian Pac J Trop Biomed 2:298-300. doi:10.1016/s2221-1691(12)60026-4

Blanford S (2012) Storage and persistence of a candidate fungal biopesticide for use against adult malaria vectors. Malar J 11:1-14

Bukhari T, Takken W, Koenraadt CJ (2011) Development of Metarhizium anisopliae and Beauveria bassiana formulations for control of malaria mosquito larvae. Parasit Vectors 4:23. doi:10.1186/1756-3305-4-23

Cancrini G, di Regalbono AF, Ricci I, Tessarin C, Gabrielli S, Pietrobelli M (2003) Aedes albopictus is a natural vector of Dirofilaria immitis in Italy. Vet Parasitol 118:195-202

Clark TB, Kellen WR, Fukuda T, Lindegren JE (1968) Field and laboratory studies on the pathogenicity of the fungus Beauveria bassiana to three genera of mosquitoes. J Invertebr Pathol 11:1-7

Darbro JM, Thomas MB (2009) Spore persistence and likelihood of aeroallergenicity of entomopathogenic fungi used for mosquito control. Am J Trop Med Hyg 80:992-997

Dee A, Belagaje RM, Ward K, Chio E, Lai MH (1990) Expression and secretion of a functional scorpion insecticidal toxin in cultured mouse cells. Biotechnol (Nature Publishing Company) 8:339-342. doi:10.1038/ng0490-339

Dimbi S, Maniania NK, Lux SA, Ekesi S, Mueke JK (2003) Pathogenicity of Metarhizium anisopliae (Metsch.) Sorokin and Beauveria bassiana (Balsamo) Vuillemin, to three adult fruit fly species: Ceratitis capitata (Weidemann), C. rosa var. fasciventris Karsch and C. cosyra (Walker) (Diptera:Tephritidae). Mycopathologia 156:375-382. doi:10.1023/b:m yco.0000003579.48647.16

Elena C, Ravasi P, Castelli ME, Peiru S, Menzella HG (2014) Expression of codon optimized genes in microbial systems: current industrial applications and perspectives. Front Microbiol 5:21. doi:10.3389/fmicb.2014.00021

Feng MG, Poprawski TJ, Khachatourians GG (1994) Production, formulation and application of the entomopathogenic fungus Beauveria bassiana for insect control: current status. Biocontrol Sci Tech 4:3-34

Feng MG, Liu CL, Xu JH, Xu Q (1998) Modeling and biological implication of time-dose-mortality data for the entomophthoralean fungus, zoophthora anhuiensis, on the green peach aphid myzus persicae. J Invertebr Pathol 72:246-251

Garcia-Munguia AM, Garza-Hernandez JA, Rebollar-Tellez EA, RodriguezPerez MA, Reyes-Villanueva F (2011) Transmission of Beauveria bassiana from male to female Aedes aegypti mosquitoes. Parasit Vectors 4:24. doi:10.1186/1756-3305-4-24

Gurevitz M, Karbat I, Cohen L, Ilan N, Kahn R, Turkov M, Stankiewicz M, Stühmer W, Dong K, Gordon D (2007) The insecticidal potential of scorpion betatoxins. Toxicon 49:473-489. doi:10.1016/j.toxicon.2006.11.015

Hegedus DD, Khachatourians GG (1995) The impact of biotechnology on hyphomycetous fungal insect. Biotechnol Adv 13:455-490

Higgs S, Olson KE, Klimowski L, Powers AM, Carlson JO, Possee RD, Beaty BJ (1995) Mosquito sensitivity to a scorpion neurotoxin expressed using an infectious Sindbis virus vector. Insect Mol Biol 4:97-103. doi:10.1111/j.1365-2583.1995.tb00013.x

Hochedez P, Jaureguiberry S, Debruyne M, Bossi P, Hausfater P, Brucker G, Bricaire F, Caumes E (2006) Chikungunya infection in travelers. Emerg Infect Dis 12:1565-1567. doi:10.3201/eid1210.060495

Jackson MA, Dunlap CA, Jaronski ST (2010) Ecological considerations in producing and formulating fungal entomopathogens for use in insect biocontrol. Biocontrol 55:129-145

Jaronski ST (2010) Ecological factors in the inundative use of fungal entomopathogens. Biocontrol 55:159-185

Jenkins NE, Thomas MB (1996) Effect of formulation and application method on the efficacy of aerial and submerged conidia of Metarhizium flavoviride for locust and grasshopper control. Pest Manag Sci 46:299-306

Kamareddine L, Fan Y, Osta MA, Keyhani NO (2013) Expression of trypsin modulating oostatic factor (TMOF) in an entomopathogenic fungus increases its virulence towards Anopheles gambiae and reduces fecundity in the target mosquito. Parasit Vectors 6:22. doi:10.1186/1756-3305-6-22

Kassa A, Stephan D, Vidal S, Zimmermann G (2004) Production and processing of Metarhizium anisopliae var. acridum submerged conidia for locust and grasshopper control. Mycol Res 108:93-100

Kirkland BH, Westwood GS, Keyhani NO (2004) Pathogenicity of entomopathogenic fungi Beauveria bassiana and Metarhizium anisopliae to Ixodidae tick species Dermacentor variabilis, Rhipicephalus sanguineus, and Ixodes scapularis. J Med Entomol 41:705-711

Labbe P, Berthomieu A, Berticat C, Alout H, Raymond M, Lenormand T, Weill M (2007) Independent duplications of the acetylcholinesterase gene conferring insecticide resistance in the mosquito Culex pipiens. Mol Biol Evol 24:1056-1067. doi:10.1093/molbev/msm025

Lacey LA, Frutos R, Kaya HK, Vail P (2001) Insect pathogens as biological control agents: do they have a future? Biol Control 21:230-248. doi:10.1006/ bcon.2001.0938

Lecuona RE, Turica M, Tarocco F, Crespo DC (2005) Microbial control of Musca domestica (Diptera: Muscidae) with selected strains of Beauveria bassiana. J Med Entomol 42:332-336

Lima EP, Paiva MH, de Araújo AP, da Silva ÉV, da Silva UM, de Oliveira LN, Santana AE, Barbosa CN, de Paiva-Neto C, Goular MO, Wilding CS, Ayres CF, de Melo-Santos MA (2011) Insecticide resistance in Aedes aegypti populations from Ceara, Brazil. Parasit vectors 4:5. doi:10.1186/1756-3305-4-5

Lomer CJ, Bateman RP, Johnson DL, Langewald J, Thomas M (2001) Biological control of locusts and grasshoppers. Annu Rev Entomol 46:667-702. doi:10.1146/annurev.ento.46.1.667

Lu D, Pava-Ripoll M, Li Z, Wang C (2008) Insecticidal evaluation of Beauveria bassiana engineered to express a scorpion neurotoxin and a cuticle degrading protease. Appl Microbiol Biotechnol 81:515-522. doi:10.1007/ s00253-008-1695-8

Matsumoto R, Shimizu Y, Howlader MT, Namba M, Iwamoto A, Sakai H, Hayakawa T (2014) Potency of insect-specific scorpion toxins on mosquito control using Bacillus thuringiensis Cry4Aa. J Biosci Bioeng 117:680-683. doi:10.1016/j.jbiosc.2013.12.004

Mburu DM, Ochola L, Maniania NK, Njagi PG, Gitonga LM, Ndung'u MW, Wanjoya AK, Hassanali A (2009) Relationship between virulence and repellency of entomopathogenic isolates of Metarhizium anisopliae and Beauveria bassiana to the termite Macrotermes michaelseni. J Insect Physiol 55:774-780. doi:10.1016/j.jinsphys.2009.04.015

Miranpuri GS, Khachatourians GG (1991) Infection sites of the entomopathogenic fungus Beauveria bassiana in the larvae of the mosquito Aedes aegypti. Entomol Exp Appl 59:19-27

Morleydavies J, Moore D, Prior C (1996) Screening of Metarhizium and Beauveria spp. conidia with exposure to simulated sunlight and a range of temperatures. Mycol Res 100:31-38

Nowierski RM, Zeng Z, Jaronski S, Delgado F, Swearingen W (1996) Analysis and modeling of time-dose-mortality of Melanoplus sanguinipes, Locusta migratoria migratorioides, and Schistocerca gregaria (Orthoptera: Acrididae) from Beauveria, Metarhizium, and Paecilomyces isolates from madagascar. J Invertebr Pathol 67:236-252

Paupy C, Delatte H, Bagny L, Corbel V, Fontenille D (2009) Aedes albopictus, an arbovirus vector: from the darkness to the light. Microbes Infect 11:1177-1185. doi:10.1016/j.micinf.2009.05.005

Pava-Ripoll M, Posada FJ, Momen B, Wang C, St Leger R (2008) Increased pathogenicity against coffee berry borer, Hypothenemus hampei (Coleoptera: (urculionidae) by Metarhizium anisopliae expressing the scorpion toxin (AalT) gene. J Invertebr Pathol 99:220-226. doi:10.1016/j.jip.2008.05.004

Qin Y, Ying SH, Chen Y, Shen ZC, Feng MG (2010) Integration of insecticidal protein Vip3Aa1 into Beauveria bassiana enhances fungal virulence to Spodoptera litura larvae by cuticle and per Os infection. Appl Environ Microbiol 76:4611-4618. doi:10.1128/AEM.00302-10

Raeder U, Rroda P (1985) Rapid preparation of DNA from filamentous fungi. pdf. Lett Appl Microbiol 1:17-20

Reynolds SE, Samuels RI (1996) Physiology and biochemistry of insect moulting fluid. In: Evans PD (ed) Advances in insect physiology, vol 26. Academic Press, Cambridge, pp 157-232. doi:10.1016/ S0065-2806(08)60031-4

Roberts DW, St Leger RJ (2004) Metarhizium spp., cosmopolitan insectpathogenic fungi: mycological aspects. Lett Appl Microbiol 54:1-70. doi:10.1016/s0065-2164(04)54001-7 
St Leger R, Joshi L, Bidochka MJ, Roberts DW (1996) Construction of an improved mycoinsecticide overexpressing a toxic protease. Proc Natl Acad Sci 93:6349-6354

St LR, Joshi L, Bidochka MJ, Roberts DW (1996) Construction of an improved mycoinsecticide overexpressing a toxic protease. Proc Natl Acad Sci USA 93:6349-6354

Stenhouse SA, Plernsub S, Yanola J, Lumjuan N, Dantrakool A, Choochote W, Somboon P (2013) Detection of the V1016G mutation in the voltagegated sodium channel gene of Aedes aegypti (Diptera: Culicidae) by allele-specific PCR assay, and its distribution and effect on deltamethrin resistance in Thailand. Parasit vectors 6:253. doi:10.1186/1756-3305-6-253

Tang QY, Feng MG (2007) DPS data processing system: experimental design, statistical analysis and data mining. Beijing, Science Press

Thomas MB, Read AF (2007) Can fungal biopesticides control malaria? Nat Rev Microbiol 5:377-383. doi:10.1038/nrmicro1638

Vessey NY, Stark PM, Flatt KL, Bueno R Jr (2008) A multiunit CO2 anesthetizing system for use in transferring mosquitoes during field cage insectcide efficacy tests. J Am Mosq Control Assoc 24:463-464. doi:10.2987/5648.1
Wang C, St Leger RJ (2007) A scorpion neurotoxin increases the potency of a fungal insecticide. Nat Biotechnol 25:1455-1456. doi:10.1038/nbt1357

Wang C, Fan M, Li Z, Butt TM (2004) Molecular monitoring and evaluation of the application of the insect-pathogenic fungus Beauveria bassiana in southeast China. J Appl Microbiol 96:861-870

WHO (2016) Mosquitoes cause millions of deaths every year. World Health Organization. http://www.who.int/neglected_diseases/vector_ecology/ mosquito-borne-diseases/en/

Wong PS, Li MZ, Chong CS, Ng LC, Tan CH (2013) Aedes (Stegomyia) albopictus (Skuse): a potential vector of Zika virus in Singapore. PLoS Negl Trop Dis 7:e2348. doi:10.1371/journal.pntd.0002348

Zlotkin E, Fishman Y, Elazar M (2000) AalT: from neurotoxin to insecticide. Biochimie 82:869-881

Zou G, Ying SH, Shen ZC, Feng MG (2006) Multi-sited mutations of beta-tubulin are involved in benzimidazole resistance and thermotolerance of fungal biocontrol agent Beauveria bassiana. Environ Microbiol 8:2096-2105. doi:10.1111/j.1462-2920.2006.01086.x

\section{Submit your manuscript to a SpringerOpen ${ }^{\circ}$ journal and benefit from:}

- Convenient online submission

- Rigorous peer review

- Immediate publication on acceptance

- Open access: articles freely available online

- High visibility within the field

- Retaining the copyright to your article 